\title{
A INTEGRAÇÃO REGIONAL E A COEXISTENNCIA ENTRE ALCA, MERCOSUL E COMUNIDADE ANDINA
}

\author{
Sergio Eduardo Canella*
}

SUMÁRIO: 1. Introdução. 2. Integração Regional: objetivos gerais e modalidades. 3. Alca, Mercosul e Comunidade Andina: breves considerações. 4. A coexistência entre Alca, Mercosul e Comunidade Andina. 5. Conclusão. 6. Bibliografia.

SUMMARY: 1.Introduction. 2. Regional integration: general objectives and modalities. 3. FTAA, Mercosul and Andean Community: brief considerations. 4. The coexistence between FTAA, Mercosul and Andean Community. 5. Conclusion. 6. Bibliografy.

SUMARIO:1. Introducción. 2. Integración regional: objetivos y modalidades generales. 3. Alca, Mercosur y Comunidad Andina: algunas consideraciones. 4. La coexistencia entre Alca, Mercosur y la Comunidad Andina. 5. Conclusión. 6. Bibliografia.

RESUMO: O objetivo neste trabalho é verificar a possibilidade de coexistência entre a Alca, Mercosul e Comunidade Andina.

ABSTRACT: The objective in this work is to verify the possibility of coexistence between the FTAA, Mercosul and Andean Community.

RESUMEN: El objetivo en este trabajo es verificar la posibilidad de coexistencia entrela Alca, el Mercosul y la Comunidad andina. 
PALAVRAS-CHAVE: Integração Regional. Alca. Mercosul. Comunidade Andina.

KEYWORDS: Regional Integration. FTAA. Mercosul. Andean Community.

PALABRAS-LLAVE: Integración Regional. Alça. Mercosur. Comunidad Andina.

\section{Introdução}

Verifica-se o desenvolvimento do direito internacional no séc. XX a partir do desencadeamento do processo de integração regional nos continentes, que surge como necessidade dos estados atingirem determinados objetivos.

A palavra de ordem para os estados é cooperação. Diante de suas deficiências os estados passam a reunir-se para atingirem objetivos comuns. Ante as necessidades apresentadas pelos estados e as metas a serem atingidas podem ocorrer aproximações nas áreas econômicas, sociais e políticas.

Os reflexos deste cenário mundial integracionalista são os mais variados e afetam os vários segmentos da sociedade de forma direta ou indireta. Năo há mais como dissociar os fenômenos e fatos internacionais do dia a dia, da realidade das grandes empresas com a possível abertura do mercado com a instituição da área de livre comercio ou dos interesses de um pequeno produtor rural com a barreira tarifarias ou não tarifárias impostas para os produtos agrícolas, por exemplo.

No continente americano não é diferente, o processo de integração regional é pauta do dia. Assim, a analise que se faz, neste momento de incertezas, é a viabilidade ou possibilidade de coexistência entre a futura Área de Livre Comércio das Américas - ALCA, Mercado Comum do Sul - Mercosul e a Comunidade Andina.

\section{A integração regional: objetivos gerais e modalidades}

A história da integração do continente americano é uma história recente, pois de uma forma geral os países estão mais direcionados para mar do que para o continente, dando as costas entre si, as cidades mais importantes estão na área litorânea e as vias terrestres de conexão são precárias e por vezes inexistentes.

No século XIX duas visões sobre a integração do continente: uma decorrente da doutrina do Presidente Monroe (1823) em que o Estados Unidos liderariam o Panamericanistno na formação de uma área de 
livre comércio e o afastamento da Inglaterra da América e a outra visão seria a de Simon Bolívar (1826), que planejava uma "comunidade" independente formada exclusivamente pelos países latinos americanos.

Assim, desde há muito, tenta-se consubstanciar no continente um projeto de integração regional. Esta integração irá surgir a partir da reunião de dois ou mais estados para a persecução de objetivos comuns baseando-se no principio da igualdade e alicerçados sobre a cooperação recíproca, constituídos solenemente por um tratado multilateral internacional.

Em geral os objetivos comuns almejados pelos estados num processo de integração regional são: o aumento do mercado consumidor, com o fluxo de pessoas e capitais; aumento de competitividade; fortalecimento econômico dos estados-membros no plano internacional; institucionalização da cooperação entre os estados-membros e, em alguns casos, a criação de órgão supranacionais.

Para fins de racionalização no campo de comércio exterior entre Estados, pode-se classificar as diversas modalidades de integração regional a partir dos seguintes conceitos idealísticos ${ }^{1}$ apresentado por Guido Fernandes Soares em: zona de livre comércio; união aduaneira; mercado comum e união econômica.

Porém antes de apresentar as características de cada modalidade, segundo Soares é importe consignar que:

"...Aspecto a ser ressaltado é que os modelos de integração não representam aperfeiçoamento uns de outros, ou que uns se transformem, pela sua simples evolução no tempo, em outros. Trata-se de tipos que, conquanto ainda não estejam bem delineados no Direito Internacional, já representam alguma racionalidade, quanto as maneiras de organização das relações internacionais, no campo do comércio exterior dos estados." ?

Em linhas gerais a zona de livre comércio tem por finalidade a supressão das barreiras alfandegárias para uma livre circulação de bens, produtos e serviços entre os paises pactuantes.

$\mathrm{Na}$ união aduaneira, os estados-membros têm por objetivo a harmonização legislativa com implementação de uma política externa comum e a adoção da Tarifa Externa Comum (TEC).

SOARES, Guido Femandes. Uniăo Europeia, Mercosul e a Proteçăo dos Direitos Humanos. In: PIOVESAN, Flavia (Coord.) Diretos Fumanos, Globalizaçáo Econômica e Integraçăo Regional. Săo Paulo: Max Limonad, 2002. p. 139

${ }^{2}$ Idem. 
O mercado comum compreende-se por algo mais avançado e complexo que incorpora uma área de livre comercio e união aduaneira e a livre circulação de pessoas com uma política econômica comum provida de organismos supranacionais.

Na união econômica encontra-se a união de todos estados do ponto de vista econômico, munidos de um banco central e moeda única.

\section{ALCA, Mercosul e Pacto Andino: breves consideraçōes}

Para que se possa realizar uma analise apurada da coexistência dos três blocos de integração regional, mister se faz tecer breves considerações sobre as bases em que são constituídos a Alca, Mercosul e Pacto Andino, bem como as modalidades de integração em que se encontram e seus respectivos objetivos.

A Área de Livre Comércio das Américas (Alca) como consta de sua denominação é um modelo de integração regional que tem por objetivo a formação de uma área de livre comércio no continente americano idealizada a partir da Cúpula da Américas realizada em dezembro de $1994 \mathrm{em}$ Miami, Estados Unidos.

Com a participação dos Chefes de Estado e de Governo das 34 democracias do continente americano (à exceção de Cuba), foi dado inicio os esforços para a formação da área de livre comércio na qual serão eliminadas progressivamente as barreiras ao comércio e ao investimento.

O compromisso da Cúpula das Américas, de 1994, traz, também, os objetivos daquele encontro e as metas e diretrizes propostas que assim foram pactuadas: fortalecimento da democracia, a erradicação da pobreza, a eliminação da discriminação, a garantia de desenvolvimento sustentável, a preservação do meio ambiente e a promoção da prosperidade por meio da integração.

O compromisso de 1994, ainda, fixa o ano de 2005 como termo para as negociações referentes a este acordo estabelecimento da Alca; prazo reiterado pelos Ministros na oitava reunião, realizada em Miami em 20 de novembro de 2003. Esta fase final das negociações da Alca será conduzida sob a co-presidência do Brasil e dos Estados Unidos.

O Mercado Comum do Sul (Mercosul) é formado pela República Argentina, a República Federativa do Brasil, a República do Paraguai e a República Oriental do Uruguai e foi constituído por meio do Tratado de Assunção assinado em 26 de março de 1991. 
Os quatro Estados Partes do Mercosul compartilham uma comunhão de valores que tem como propósito a livre circulação de bens serviços e fatores produtivos, o estabelecimento de um Tarifa Externa Comum e a harmonização de leis internas para o fortalecimento do processo de integração.

Em dezembro de 1994, aprovou-se um Protocolo Adicional ao Tratado de Assunção, denominado Protocolo de Ouro Preto, na qual se estabeleceu a estrutura institucional do Mercosul, dotandoo de personalidade jurídica internacional.

Em função das crises econômicas e institucionais, no ano 2000 os paises do cone sul decidiram encarar uma nove etapa do processo de integração com o relançamento do Mercosul, tendo como objetivo principal reforçar a União Aduaneira, fase em que ainda se encontra.

Houve, também, neste momento, a adoção do Protocolo de Olivos para a Solução de Controvérsias, que veio ratificar o interesse dos paises integrantes do Mercosul na consolidação e aprofundamento do bloco.

O Grupo Andino (denominação inicial) é uma organização de integração sub-regional com personalidade jurídica internacional, constituída por meio do Acordo de Cartagena, celebrado em 26 de maio de 1969, hoje, formado por Bolívia, Colômbia, Equador, Peru e Venezuela.

Conforme o Art. $1^{\underline{3}}$ do Acordo de Cartagena a integração tem por objetivos: “...el desarrollo equilibrado y armónico de los Países Miembros en condiciones de equidad, mediante la integración y la cooperación económica y social; acelerar su crecimiento y la generación de ocupación; facilitar su participación en el proceso de integración regional, con miras a la formación gradual de un mercado común latinoamericano."

Após a crise do petróleo na década de setenta, aumento da dívida externa, recessão e estagnização das economias dos sócios andinos, o grupo teve alavancado o seu processo de integração nos anos noventa, a partir da aprovação do protocolo que modificou o Acordo de Cartagena, adotado em Trujillo, Perú em março de 1996 e que criou a Comunidade Andina de Nações (CAN) estabelecendo o Sistema Andino de Integração (SAI), institucionalizando e consolidando normativamente seus órgãos mais importantes: Secretaria geral, Tribunal de Justiça e Parlamento Andino.

Mônica Rossel apresenta as características essenciais da Comunidade Andina: “...Tres características esenciales de la Comunidad Andina: la existencia de un orden jurídico andino, su supranacionalidad y la existencia de órganos comunitarios también supranacionales encargados de la administración de la justicia andina en las instancias administrativas (Secretaría General) y judicial (Tribunal del Justicia del Acuerdo de Cartagena). A ellos se puede 
sumar una cuarta característica y es la relativa al hecho de que las normas comunitarias que abarcan un espectro cada vez más amplio de áreas de la actividad tanto económica como social."

José Antonio Pejovés explicita o regime jurídico encontrado na Comunidade Andina a ser destacado no continente americano:

"... Las decisiones son leyes comunitarias que se aplican directamente en los cinco países y tienen primacía sobre las leyes domésticas, pues así lo estatuye el Tratado de Creación del Tribunal de Justicia de la Comunidad Andina, cuerpo normativo que junto con el Acuerdo de Cartagena y sus protocolos modificatorios, tienen carácter constitucional dentro de la Subregión andina."

Ainda que existam tais evoluções em seu regime político e juridico, frisa-se que o almejado mercado comum ainda está em fase de construção, colocando-os em um momento de união aduaneira.

O projeto andino, no entanto, é mais ambicioso que o Mercosul e visa a construção de um mercado comum latino-americano, enquanto que o Mercosul tem vistas a formar um mercado comum entre os seus estados-partes.

Neste contexto, muito embora os olhos cone sul estejam, por vezes, voltados a União Européia, o processo de integração sub-regional firmado pelos paises andinos pode servir de paradigma para o desenvolvimento do Mercosul, seja pela aproximação das realidades socioeconômicas ou dos avanços verificados na Comunidade por meio da instituição de órgãos comunitários, um ordenamento jurídico andino e de seus caracteres de supranacionalidade.

\section{A Coexistência entre a Alca, Mercosul c Comunidade Andina}

Os países do continente americano estão passando por um momento crucial em que terão de decidir se farão ou não parte da Área de Livre Comércio das Américas (ALCA) e em que condiçóes participarão ou não deste processo.

Muito embora não dê, ainda, para prever com precisão os efeitos vindouros das opçóes ofertadas, não resta dúvida, que qualquer que seja a ação ou omissão política, na atual conjuntura, não só trará reflexos no futuro político e econômico do continente, mas também, certamente, no futuro dos importantes organismos de integração regional para a formação de mercado comum existentes na América latina como o Mercosul e a Comunidade Andina.

\footnotetext{
- ROSELL, Monica. Marco institucional y seguridad jurídica en la Comunidad Andina. disponivel em http//www.comunidadandina.org/normativa/doctrina/doctrina03.htm. acesso em 08/01/2004.

"PEJOVES, José Antonio. La modernización del Derecho de la competencia en la CAN. Disponivel em http:/www.comunidadeandina.org/prensa/articulos/gestisn21-3-03.htm. acesso em 08/01/2004. 
A priori a implantação da Área de livre Comercio das Américas não pressupõe a eliminação dos acordos firmados entre os paises integrantes do Mercosul e da Comunidade Andina e, sequer exige que estes blocos deixem de existir.

No item 5 da Declaração Ministerial de Belo Horizonte firmada em 16 de maio de 1997, acordam os paises integrantes que existe um grau significativo de convergência nas seguintes questões:

“a. (...) A ALCA poderá coexistir com acordos bilaterais e sub-regionais, na medida em que os direitos e obrigações assumidos ao amparo desses acordos não estejam cobertos pelos direitos e obrigações da ALCA, ou os ultrapassem". "d. os países poderão negociar e aderir à ALCA individualmente ou como membros de um grupo de integração sub-regional que negocie como uma unidade". 6

No entanto, ainda que haja previsão de adesão e negociação dos paises de forma individual ou como membros de um grupo de integração sub-regional, uma interpretação preliminar da alínea "a", indica que deverá haver uma subordinação de todos acordos bilaterais e sub-regionais existentes a Alca.

Isto implica em dizer que embora os objetivos do Mercosul e da Comunidade Andina estejam voltados para a persecução de um mercado comum, área mais complexa e com maior profundidade nas relações entre seus pares, à Área de Livre Comércio das Américas possui um alcance econômico maior e, conforme suas disposições, submeterá as disposições dos acordos firmados entre os paises integrantes do Mercosul e da Comunidade Andina a sua chancela.

Assim, os acordos a serem firmadas no âmbito da Alca, poderão atingir pontos sensíveis e cruciais dos blocos sub-regionais, se não os fazendo desaparecer, diminuindo a sua importância.

Talvez o foco de analise deva ser a sobrevivência do bloco do cone sul e andino, uma vez que a questão pertinente não seria a existência simultânea, mas permanência de forma atuante.

Na medida em que a atual zona aduaneira imperfeita em consolidação não tem prioridade em relação a Alca, já que as matérias da Área de Livre Comércio das Américas se mostram mais profundas e abrangentes que as do Mercosul, a tendência é que este seja absorvido pelo bloco das Américas, nos moldes em que se deu o Benelux com a formação da União Européia.

Pontualmente assinala Paulo Roberto de Almeida na práxis que: "Em suma o Mercosul é uma modesta construção integracionista que funciona em regime de condomínio, com relativa permeabilidade e

" Dedaração Mnisteral de Belo Horizonte. disponivel em http//www.ftaa-alca.org/ministerials/ belo p.asp. Acesso em 09/012004. 
associativismo entre os seus, até agora, poucos membros. A Alca apresenta-se como um imenso edificio de escritórios, onde a impessoalidade de trato e a frieza de regras padronizadas prometem poucos momentos de excitação e muitos anos de aborrecimento."

Almeida explicita que uma vez que o Mercosul é uma construção política com objetivos sociais, administrativos com vistas à justiça, turismo, cultura, ciência, educação, previdência social, sua sobrevivência frente a Alca não está ameaçada de forma absoluta, estando preparado para enfrentar desafios do tipo comercial e econômico. ${ }^{\text {. }}$

Porém, não há como dissociar as decisões e políticas econômicas de uma região com um importante mercado de projetos e metas políticas, sociais ou de qualquer outro fim, ficando estas questôes de uma forma ou de outra sujeitas às decisões macroeconômicas do bloco continental.

Neste mesmo diapasão, encontra-se a Comunidade Andina, que terá de submeter os seus órgãos administrativos e as decisões normativas comunitárias emanadas de seu Tribunal de Justiça à compatibilidade com as tratativas e decisōes promovidas no âmbito do Alca, uma vez que esta possui como principio que todos os países devem assegurar que suas leis, regulamentos e procedimentos administrativos estejam em conformidade com as obrigações assumidas no acordo da ALCA.

Do mesmo modo o projeto de formação de uma Área de Livre Comércio Sul-Americana (ALCSA), constituída entre o Mercosul e a Comunidade Andina poderia sucumbir diante do projeto mais ambicioso que é a Alca, liderada pela maior potencia econômica do mundo.

Antes de qualquer encantamento teórico com a proposta americana de integração das Américas é necessário apontar os interesses envolvidos na negociação.

Frisando que, embora os interesses sejam diversos, pois envolve trinta e quatro países do continente, nem todos serão determinantes na configuração das negociações, aliảs, não obstante a retórica da igualdade entre os estados, o interesse que poderá prevalecer será, essencialmente, o do Estados Unidos; e assim será não só pela evidente constatação de sua hegemonia econômica e militar, mas, sobretudo, em função da estrutura constitucional e legislativa daquele país, que só reconhecerá no campo jurídico o que for, finalmente, aprovado pelo seu Congresso de acordo com sua política econômica externa, reflexo dos interesses comerciais internos.

\footnotetext{
"ALMEIDA, Paulo Roberto de. Um Balanço do Mercosul em sua Primeira Decada: Realizaços e Perspectivas, Disponivel em http//www.iadb.org/search97cg/s97is.dil. acesso em 0701.2004. 
Contudo, só as negociações definirão se o Mercosul e a Comunidade Andina será, ou não, capaz de permanecer sem diluir-se ante um projeto que, em curto prazo, não é atraente sob o ponto de vista econômico, nem aceitável, sob o ponto de vista político, exceto se os seus participantes não tiverem projetos autônomos de desenvolvimento ou não tiverem atingido uma maturidade na integração capaz de resistir aos interesses e manobras estadosunidenses, que serão inúmeras, em busca da consolidação da Alca.

O continente americano está diante de um conflito dos dois modelos: ou o continente se "Naftaliza" por meio da Alca ou "Mercoliniza" com a expansão dos acordos quadros (4+1).

Neste contexto de incertezas e prorrogações de negociação, a aproximação que vem se consubstanciando entre o Mercosul e a Comunidade Andina, com vistas à formação futura de uma área de livre comércio latino-americana, se bem conduzidas, podem criar novas perspectivas para a integração regional com o fortalecimento destes blocos e, sem dúvida, para as negociações perante a Alca.

\section{Conclusão}

A integração regional surge efetivamente no século XX como instrumento utilizado pelos estados para dirimir suas contingências sociais e econômicas e buscar espaço no competitivo mercado mundial a partir de um processo gradual de cooperação internacional.

Em meio às negociações da Alca, cabe a cada Estado ou bloco subregional "optar" ou não pela sua participação, desde que identifique a modalidade de integração que irá participar, reconheça as suas limitações socioeconômicas, não ceda a pressões de natureza econômica ou política e saiba identificar os percalços da sua ausência num processo integracionista em formação na região geográfica em que está situado.

Mister, assim, que os paises da América do Sul, especialmente aqueles participes dos blocos sub-regionais (Mercosul e Comunidade Andina) posicionarem-se conjuntamente a fim de fazer frente às investidas econômicas, psicológicas e diplomáticas dos Estados Unidos da América, para que ao invés de uma área de livre comercio, não tenhamos a proliferação transfronteiriça da pobreza, tão acentuada nos paises do hemisfério sul.

Notadamente o projeto norte-americano de criar uma área de livre comércio entre o Alasca e a terra do Fogo, sem a presença dos paises integrantes do Mercosul e da Comunidade Andina não sobreviveria, talvez aqui esteja a força destes blocos sub-regionais. 


\section{BIBLIOGRAFIA}

Acordo de Cartagena, disponivel em http://www.comunidadeandina.org. acesso em 28/12/2003.

ALMEIDA, Paulo Roberto de. Um Balanço do Mercosul em sua Primeira Década: Realizações e Perspectivas. Disponível em http:/www.iadb.org/ search $97 \mathrm{cgi} / \mathrm{s} 97$ is.dll. acesso em 07.01.2004.

BARRAL, Welber (org.). Negociações comerciais multilaterais. Florianópolis: Fundação Boiteux, 2003.

BENECKE, Dieter W.; NASCIMENTO, Renata, FENDT, Roberto (orgs). Brasil na arquitetura global. Rio de Janeiro: Konrad Adenauer, 2003. PEJOVES, José Antonio. La modernización del Derecho de la competencia en la CAN. disponivel em http://www.comunidadandina.org/prensa/ articulos/gestion21-3-03.htm. acesso em 08/01/2004

Declaração Ministerial de Belo Horizonte. disponivel em http:/ www.ftaaalca.org/ministerials/belo_p.asp. Acesso em 09/012004

RESEK, José Francisco. Direito Internacional Público: Curso Elementar. $8^{a}$ Ed. São Paulo: Saraiva, 2000.

ROSELL, Monica. Marco institucional y seguridad jurídica en la Comunidad Andina. Abril de 1999. disponível em: < http:/ www.comunidadandina.org/ normativa/doctrina/doctrina03.htm>. acesso em 08/01/2004.

SILVA, Roberto Luiz; Mazzuoli, Valério Oliveira (Orgs.). O Brasil e os acordos econômicos internacionais. São Paulo: Revista dos Tribunais,2003.

SOARES, Guido Fernandes. União Européia, Mercosul e a Proteção dos Direitos Humanos. In: PIOVESAN, Flavia (Coord.) Dircitos Humanos, Globalização Econômica e Integração Regional. São Paulo: Max Limonad, 2002. p. 121-169.

TRÉRET, Bruno; BRAGA, José Carlos de Souza (Orgs.). Regulação econômica e globalização. Campinas, SP: UNICAMP. IE, 1998. 